\title{
PRODUÇÃO E CARACTERIZAÇÃO DE NANOPARTÍCULAS DE ÁCIDOS HÚMICOS POR NANOPRECIPITAÇÃO
}

\author{
B. A. G. MELO ${ }^{1}$, F. L. MOTTA ${ }^{1}$, M. H. A. SANTANA ${ }^{1}$ \\ ${ }^{1}$ Universidade Estadual de Campinas, Departamento de Engenharia de Materiais e Bioprocessos. \\ E-mail para contato: g.melo.bruna@gmail.com
}

\begin{abstract}
RESUMO - Ácidos húmicos (AH) são complexos poliméricos de ácidos orgânicos constituídos por diversos grupos funcionais que atuam em várias aplicações, algumas já bem estabelecidas como na agricultura e outras com grande potencial em fármacos e cosméticos. Com o objetivo de contribuir para as aplicações farmacêuticas e em cosméticos, este trabalho apresenta um estudo da produção de nanopartículas de $\mathrm{AH}$ mediada pela redução da sua solubilidade com o pH e agitação mecânica. A dispersão do polímero em nanopartículas é vantajosa por aumentar a área superficial, que tende a melhorar a sua eficiência de ação no meio biológico. As partículas foram caracterizadas pelo diâmetro médio, distribuição populacional, morfologia e potencial zeta. Os resultados mostram a factibilidade da produção de nanopartículas esféricas de $\mathrm{AH}$, em processo simples, escalonável e de etapa única. As propriedades fisico-químicas das nanopartículas foram controladas pela razão molar entre $\mathrm{NaOH}$ e $\mathrm{HCl}$, usado inicialmente para a solubilização do AH. O compromisso entre as concentrações iniciais do ácido e base, $\mathrm{pH}$ final, grau de dissociação e as propriedades das nanopartículas é discutido com base nos resultados obtidos.
\end{abstract}

\section{INTRODUÇÃO}

Ácidos húmicos (AH) são macromoléculas orgânicas constituídas de diversos grupos funcionais, que vêm sendo amplamente usados na agricultura como nutriente de solo e também como fungicida. Dentre os seus grupos funcionais estão os aromáticos, que não lhe conferem toxicidade (Thiel et al., 1981), e os grupos carboxílicos que são responsáveis pelas suas características fungicidas (Siddiqui et al., 2009). Na área de cosméticos os AH são usados em máscaras para tratamento facial, sendo também reconhecidos como compostos dermatocosméticos e dermoterapêuticos (Wollina, 2009).

As moléculas de AH são formadas por uma longa cadeia polimérica com porções hidrofóbicas e hidrofílicas que, em meio alcalino, onde são solúveis, adotam uma configuração estendida devido à desprotonação dos grupos carboxílicos e hidroxilas e à repulsão entre as cargas negativas (Figura 1A). Na presença de cátions, a repulsão das cargas é minimizada, fazendo com que a cadeia se enovele e adquira uma estrutura compacta, com sua porção hidrofóbica ficando no interior e a hidrofílica em contato com o meio ocorrendo assim sua precipitação (Figura 1-B). 


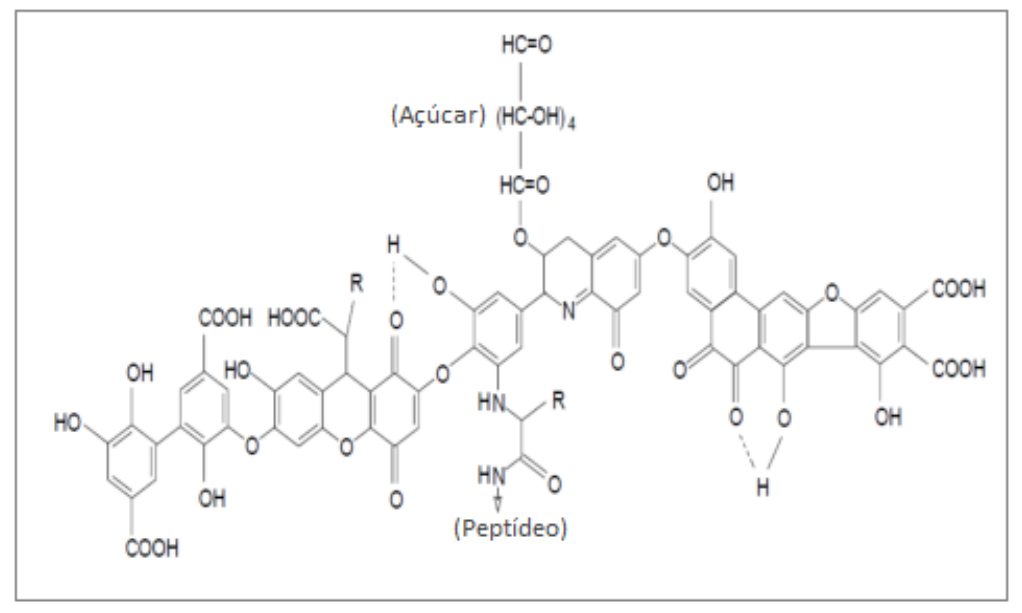

(A)

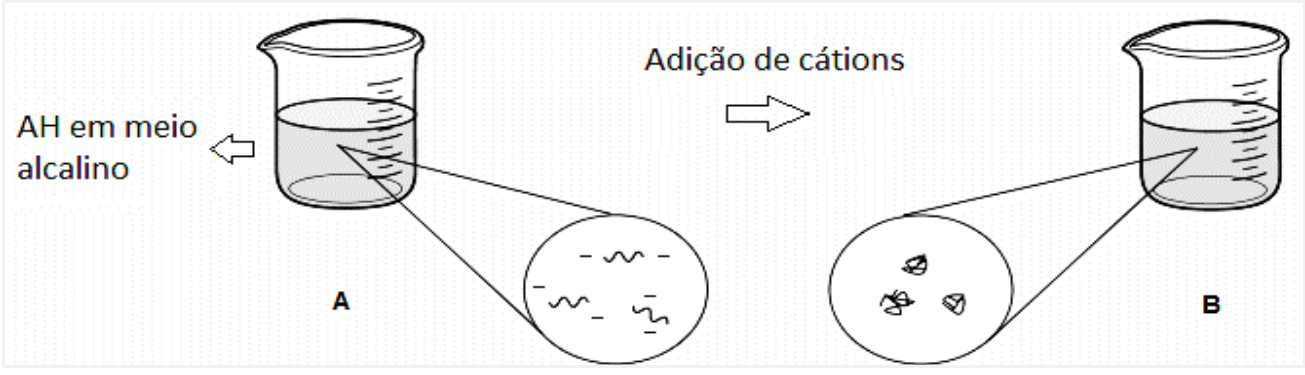

(B)

Figura 1- (A) Modelo de estrutura dos AH de acordo com Stevenson (1982); R pode ser alquil, aril ou aralquil. (B) Moléculas precipitadas de AH após adição de cátions ao meio com conformação compacta.

Estudos anteriores demonstraram a agregação de moléculas de $\mathrm{AH}$ com o abaixamento do pH e completa precipitação em pHs muito ácidos, entre 2 e 3. A agregação mediada por cátions metálicos conduz à formação de pseudo-micelas, assim denominadas por semelhança com micelas de tensoativos, as quais também precipitam através de um processo sequencial de intra e inter-agregação, conforme evidenciado por von Wandruszka et al. (1997), a partir do comportamento de fluorescência de espécies não polares, como o pireno, em solução de AH.

Em geral, a formação de nanopartículas por precipitação de um polímero dissolvido em solvente, ocorre após a adição de um não solvente, no qual o solvente é miscível. Entretanto, a nanoprecipitação também pode ser mediada pela adição de cátions ou outros polímeros de carga oposta (Schubert et al., 2011; Bicudo, 2012). Em todos os casos, a agitação mecânica tem a função de homogeneizar o meio e reduzir a agregação inter-partículas.

O presente trabalho teve como objetivo o estudo da produção de partículas de $\mathrm{AH}$ por nanoprecipitação mediada pela redução do pH e agitação mecânica do meio. 


\section{MATERIAL E MÉTODOS}

\subsection{Produção de nanopartículas de AH por nanoprecipitação}

Seis ensaios foram realizados em triplicata para estudar a produção de $\mathrm{AH}$ pelo processo da nanoprecipitação mediada pelo pH e agitação mecânica. Nesses ensaios variaram-se a concentração e o volume da solução de $\mathrm{HCl}$ adicionados à solução de $\mathrm{NaOH}$ usada para solubilizar inicialmente os AH comerciais (Sigma-Aldrich).

Os AH na forma de pó, com tamanhos de partículas variados, foram adicionados a uma solução de $\mathrm{NaOH} 0,1 \mathrm{~N}$, de modo a obter-se uma concentração de $5 \mathrm{mg} / \mathrm{L}$. Para auxiliar na dissolução, a solução foi deixada sob agitação magnética por 10 minutos e, posteriormente, por 5 minutos em banho sonicador. Foram preparados seis frascos contendo $5 \mathrm{~mL}$ dessa solução onde, sob agitação mecânica $(400 \mathrm{rpm})$ e temperatura controlada $\left(20^{\circ} \mathrm{C}\right)$, a solução de $\mathrm{HCl}$ foi gotejada com auxílio de micropipeta, de acordo com os ensaios mostrados na Tabela 1.

Tabela 1 - Valores de concentração de $\mathrm{HCl}$ e razão $\mathrm{NaOH} / \mathrm{HCl}$ utilizada para a nanoprecipitação dos AH

\begin{tabular}{|c|c|c|c|c|}
\hline Ensaio & $\begin{array}{c}\text { Concentração } \\
\text { HCl (M) }\end{array}$ & $\begin{array}{c}\text { Número de } \\
\text { mols HCl }\end{array}$ & $\begin{array}{c}\text { Número de } \\
\text { mols NaOH }\end{array}$ & $\begin{array}{c}\text { Razão molar } \\
\text { NaOH/HCl }\end{array}$ \\
\hline $\mathbf{1}$ (controle) & 0 & 0 & $5,0 \mathrm{E}-4$ & -- \\
\hline $\mathbf{2}$ & 0,05 & $1,0 \mathrm{E}-5$ & $5,0 \mathrm{E}-4$ & 50 \\
\hline $\mathbf{3}$ & 0,05 & $2,0 \mathrm{E}-5$ & $5,0 \mathrm{E}-4$ & 25 \\
\hline $\mathbf{4}$ & 0,5 & $1,0 \mathrm{E}-4$ & $5,0 \mathrm{E}-4$ & 5 \\
\hline $\mathbf{5}$ & 0,5 & $2,0 \mathrm{E}-4$ & $5,0 \mathrm{E}-4$ & 2,5 \\
\hline $\mathbf{6}$ & 1 & $2,0 \mathrm{E}-4$ & $5,0 \mathrm{E}-4$ & 2,5 \\
\hline $\mathbf{7}$ & 1 & $4,0 \mathrm{E}-4$ & $5,0 \mathrm{E}-4$ & 1,3 \\
\hline $\mathbf{8}$ & 5 & $1,0 \mathrm{E}-3$ & $5,0 \mathrm{E}-4$ & 0,5 \\
\hline $\mathbf{9}$ & 5 & $2,0 \mathrm{E}-3$ & $5,0 \mathrm{E}-4$ & 0,25 \\
\hline
\end{tabular}

\subsection{Caracterização}

Amostras de cada um dos ensaios foram coletadas e caracterizadas quanto ao diâmetro médio e polidispersidade, sendo realizadas três medidas para cada ensaio, através de espalhamento de luz utilizando laser de alta potência, em equipamento Autosizer 4700, Zetasizer Nano (Malvern) com ângulo de $173^{\circ} \mathrm{C}$ em relação ao feixe de luz incidente (laser He-Ne). Os resultados foram analisados em termos de intensidade de luz espalhada (distribuição I) e de distribuição populacional em número de partículas predominantes (distribuição $\mathrm{N}$ ). $\mathrm{O}$ potencial zeta foi caracterizado no mesmo equipamento, realizando-se três medidas para cada ensaio.

A morfologia, assim como a distribuição das nanopartículas na dispersão, foi determinada por microscopia eletrônica de varredura (MEV), (Leo 440i, LEO Electron Microscopy/Oxford, 
Cambridge, Inglaterra). A voltagem de aceleração foi de $20 \mathrm{kV}$ e a corrente do feixe igual a $100 \mathrm{pA}$. A amostra recebeu pulverização catódica (SC7620, VG Microtech, Inglaterra) com $92 \mathrm{~A}^{\circ} \mathrm{de}$ espessura de Au.

\section{RESULTADOS E DISCUSSÃO}

A Figura 2 mostra a distribuição de tamanhos das partículas de $\mathrm{AH}$ referentes aos ensaios 1 (controle), 5, 7 e 8, cujas razões base/ácido foram de 2,5; 1,3 e 0,5 respectivamente.

As caracterizações foram realizadas quanto à distribuição de intensidade de luz espalhada pelas partículas (distribuição-I), que é a primeira distribuição gerada pela análise de dados, e a partir dela se obtém a distribuição populacional em número de partículas (distribuição-N). As distribuições I e $\mathrm{N}$ são proporcionais ao diâmetro das partículas elevado à sexta e primeira potência, respectivamente, e portanto, é necessário considerar as duas distribuições para análise mais completa dos resultados.

A distribuição-I do ensaio controle mostra uma grande variedade de tamanhos, enquanto a distribuição-N apresentou diâmetro médio em torno de $80 \mathrm{~nm}$.

Com a adição de $\mathrm{HCl}$ a distribuição-I passa a ser mais homogênea, como observado no ensaio 5. $\mathrm{O}$ diâmetro médio das partículas de $\mathrm{AH}$ aumentou com a adição do ácido, sendo este $190 \mathrm{~nm}$ para o ensaio 5, $600 \mathrm{~nm}$ para o ensaio 7 e $1200 \mathrm{~nm}$ para o ensaio 8. Este último obteve também populações mais heterogêneas, como é possível observar na sua distribuição-I, e confirmado pela medida do índice de polidispersidade, que foi de 0,505 , enquanto que para todos os outros ensaios esse índice variou entre 0,300 e 0,400 .

As imagens obtidas por microscopia eletrônica de varredura (MEV) dos ensaios 5 e 8, indicam a formação de partículas esféricas e nas dimensões verificadas na análise de diâmetros. A Figura 3 mostra que as nanopartículas obtidas no ensaio 5, de razão $\mathrm{NaOH} / \mathrm{HCl}$ igual a 2,5, estão bastante dispersas na solução, com apenas alguns pontos de agregação. Na Figura 4 é possível observar que as nanopartículas obtidas através da adição de $\mathrm{HCl} 5 \mathrm{M}$, de razão base/ácido igual a 0,5 se agregaram, devido à sua desestabilização eletrostática. É possível observar também que houve formação de cristais de $\mathrm{NaCl}$ devido ao excesso de ácido adicionado, o que não foi constatado no ensaio 5 .

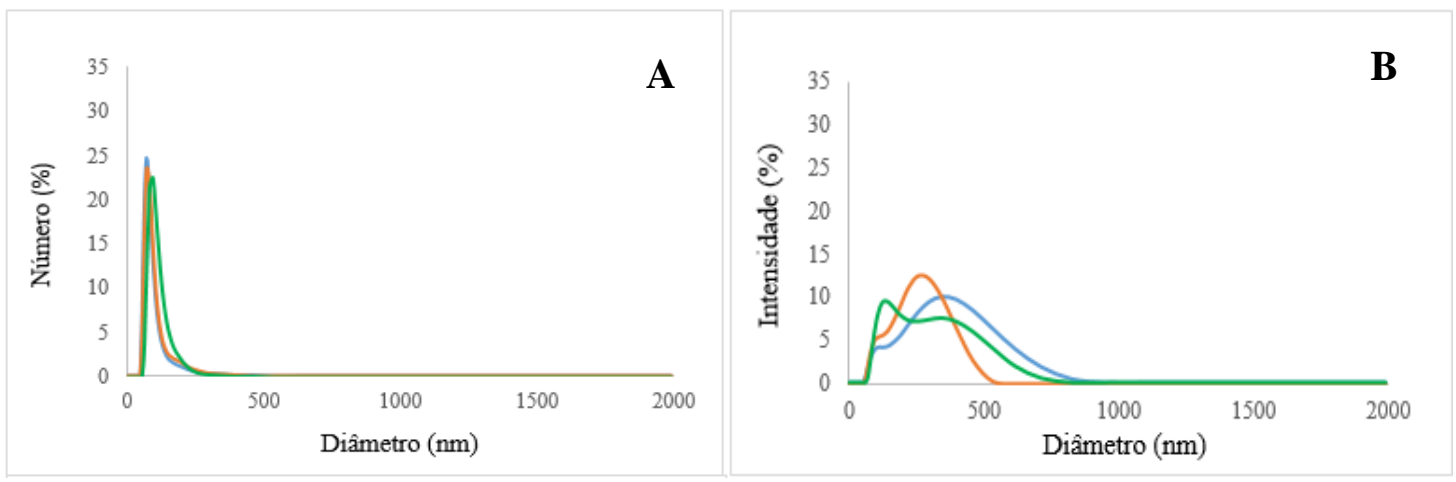



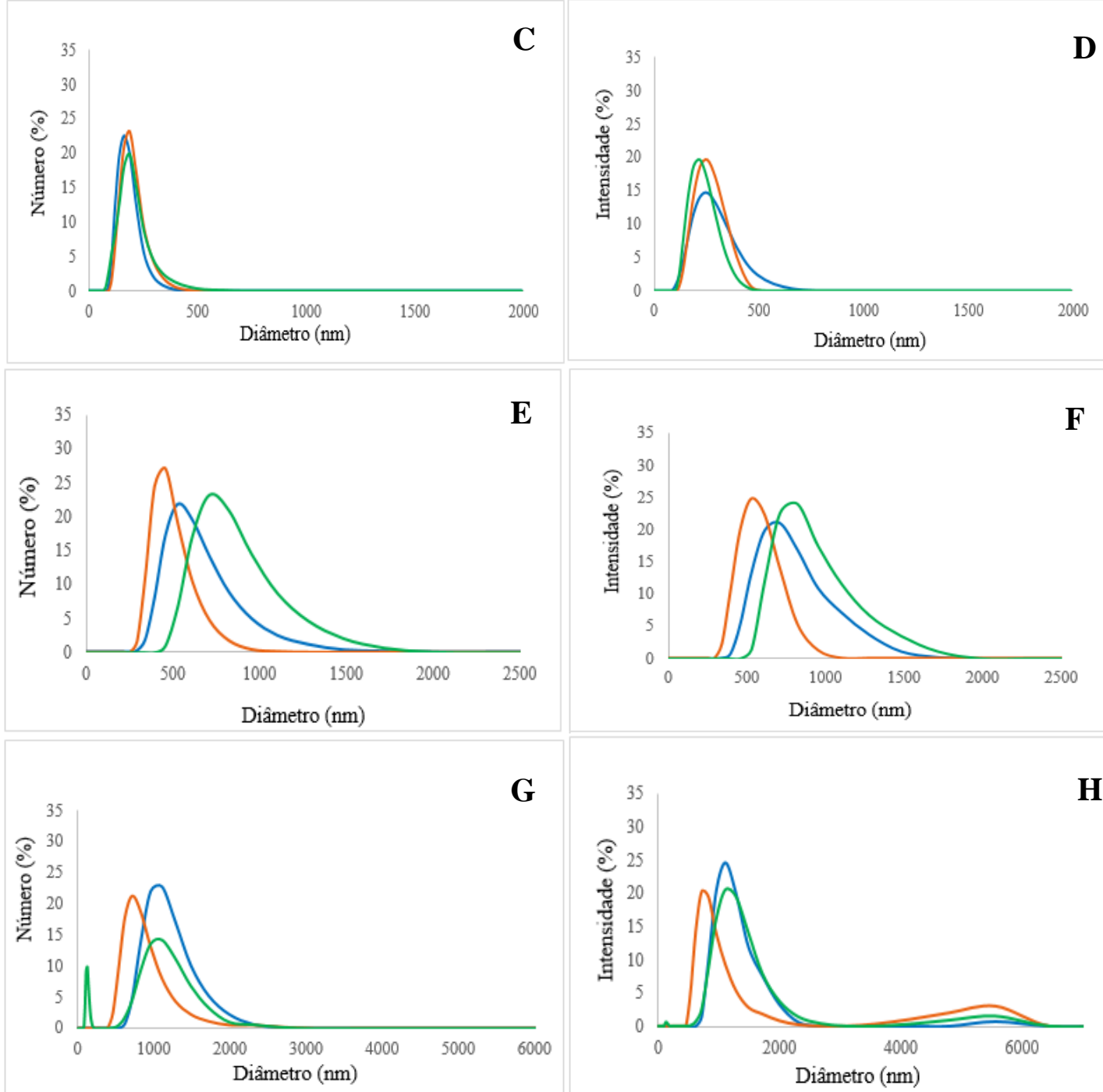

Figura 2 - Distribuições populacionais de diâmetros das partículas em número (distribuição- N), curvas à esquerda e em intensidade (distribuição -I), curvas à direita. Ensaio controle, sem adição de $\mathrm{HCl}$ (A e B); Ensaio 5, de razão base/ácido igual a 2,5 (C e D); Ensaio 7, de razão igual a 1,3 (E e F) e Ensaio 8, de razão igual a $0,5(\mathrm{G}$ e $\mathrm{H})$. As curvas representam o valor médio de cada triplicata. 


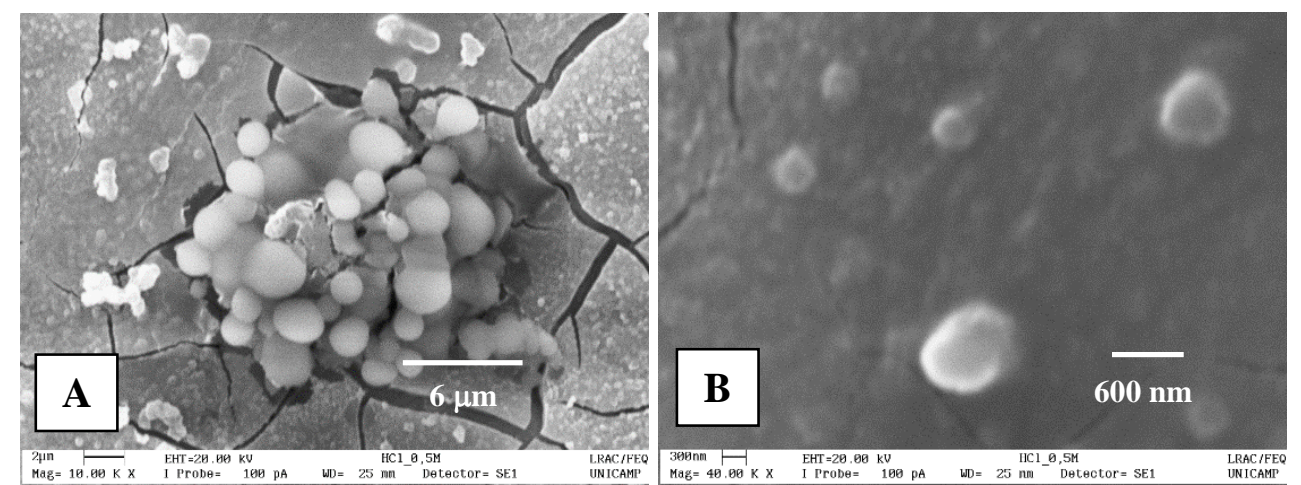

Figura 3 - Imagens das partículas de AH produzidas por nanoprecipitação através da adição de $200 \mu \mathrm{L}$ de $\mathrm{HCl}$ 0,5 M, obtida por MEV. Partículas maiores agregadas (A) e nanopartículas dispersas (B).
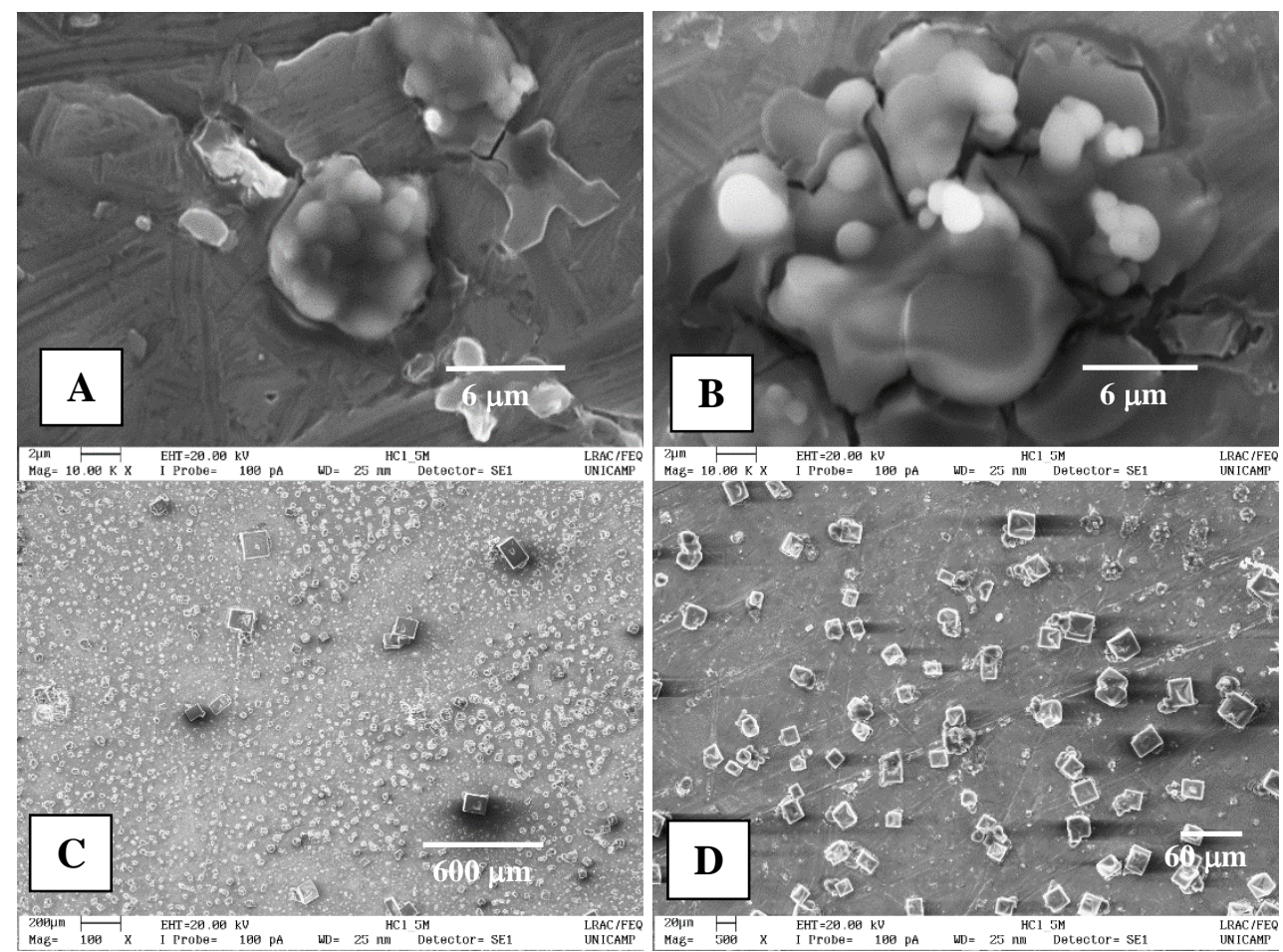

Figura 4 - Imagens das partículas de AH produzidas por nanoprecipitação através da adição de $400 \mu \mathrm{L}$ de $\mathrm{HCl} 5 \mathrm{M}$, obtida por MEV. Diferentes pontos de aglomeração das partículas (A e B) e cristais de $\mathrm{NaCl}$ formados pelo excesso de ácido (C e D).

A Figura 5 mostra os resultados das análises de potencial zeta correspondentes aos ensaios realizados (Tabela 1). O valor do potencial zeta permaneceu igual ao controle até a concentração de 1 $\mathrm{M}$, indicando que as modificações de carga na camada de Stern foram significativas somente a partir dessa concentração, e à menor razão molar. Com $5 \mathrm{M}$ de $\mathrm{HCl}$, o potencial zeta foi praticamente reduzido a zero. 
A análise conjunta das distribuições de diâmetros e potencial zeta indicam que as interações intra-moleculares ocorreram predominantemente nos ensaios 2 a 6 , enquanto que nas condições dos ensaios 7 a 9 houve também interações inter-moleclares que favoreceram a agregação das partículas, com consequente instabilidade eletrostática. Em todos os casos, o pH final das dispersões ainda foi distante do $\mathrm{pH}$ neutro, indicando a necessidade de redução das concentrações de ácido e base para as mesmas razões estudadas.

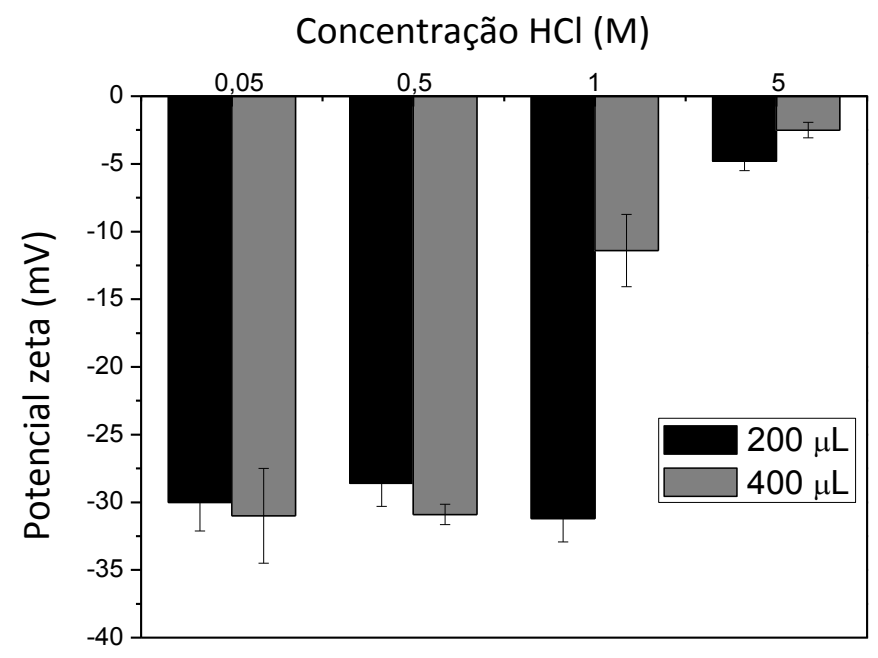

Figura 5 - Potencial zeta das partículas de AH em função da concentração de $\mathrm{HCl}$.

\section{CONCLUSÕES}

Os resultados obtidos mostram que a produção de nanopartículas de AH por nanoprecipitação é factível, e é controlada pela razão base/ácido. Trabalhos futuros devem otimizar as concentrações iniciais de ácido e base utilizadas, para as mesmas razões, assim como avaliar a possibilidade de utilização de ácidos fracos.

\section{REFERÊNCIAS}

BICUDO, R. C. S.; SANTANA, M. H. A. Production of hyaluronic acid (HA) nanoparticles by a continuous process inside microchannels: Effects of non-solvents, organic phase flow rate, and HA concentration. Chem. Eng. Sci., v. 84, p. 134-141, 2012.

SCHUBERT, S.; DELANEY, J. T.; SCHUBERT, U. S. Review nanoprecipitation and nanoformulation of polymers: from history to powerful possibilities beyond poly(lactic acid). $J . R$. Soc. Chem., v. 7, p. 1581-1588, 2011.

SIDIQUI, Y.; MEON S.; ISMAIL, R.; RAHMANI, M.; ALI A. In vitro fungicidal activity of humic acid fraction from oil palm compost. Int. J. Agr. Biol., v. 11, p. 448-452, 2009. 
THIEL, K. D.; HEIBIG, B., KLOCHING R.; VUTZIER, P., SPROSSIG; M. SCHWEIZER, H. Comparison of the in vitro activities of ammonium humate and of enzymically oxidized chlorogenic and caffeic acids against type 1 and type 2 human herpes virus. Pharmazie, v. 36; p. 50-53, 1981.

UWE WOLLIN. Peat: a natural Source for dermatocosmetics and dermatotherapeutics. J. Cutan. Aesthet. Surg., v. 2, p. 17-20, 2009.

VON WANDRUSZKA, R.; RAGLE, C.; ENGEBRETSON, R. The role of selected cations in the formation of pseudomicelles in aqueous humic acid. Talanta, v. 44, p. 805-809, 1997. 